\title{
Single jersey modal fabrics-better choice for sportswear applications
}

\begin{abstract}
This study aimed at producing knitted fabrics with good comfort level. First, short staple yarns of Cotton \& Modal were spun having linear densities 15Tex, and 20Tex. Then, Single Jersey knitted fabrics were produced with different tightness factor with these yarns and the thermal comfort parameters of fabrics-thermal conductivity, thermal resistance were measured on Laser Comp model Fox 314 and air permeability. It was found that modal fabrics with single jersey structure are preferable for mild activities.
\end{abstract}

Volume 2 Issue $6-2017$

\author{
Jitendra R Ajmeri,' SS Bhattacharya² \\ 'Department of Textile Technology, Sarvajanik College of \\ Engineering and Technology, India \\ ${ }^{2}$ Department of Textile Engineering, MS University, India
}

Correspondence: Jitendra R Ajmeri, Textile Technology Department, Sarvajanik College of Engineering and Technology, Surat, India, Tel 9898374017, Email jitendra.ajmeri@scet.ac.in

Received: January 30, 2017 | Published: September 19, 2017

\section{Introduction}

The demands from fabrics have changed with the developments in textile technology and the rise of people's living standards. The requirement is not just style and durability, but also clothing comfort. Clothing comfort, being a fundamental and universal need for consumers, may be defined as a pleasant state of physiological, psychological and physical harmony between a human being and the environment. Physiological comfort is related to the human body's ability to maintain life, psychological comfort to the mind's ability to keep itself functioning satisfactorily with external help and includes the aesthetic appeal which depends on size, fit, colour, luster, style, fashion compatibility, etc., and physical comfort to the effect of the external environment on the body. Comfort is one of the most important aspects of clothing, as it strongly affects the choice of people when buying the clothes. ${ }^{1}$

Designing clothing for the leisure sports is really difficult as far as physiological requirements are concerned as these are often contradictory due of the varying climate and activity level. It is a challenging task to optimize sportswear as regards to thermophysiological and sensorial comfort. It has been observed that leisure sports are characterized by the fact that maximum physical performance is not always achieved and that active phases are interspersed with rest phases. In addition, a leisure sportsperson often wears his/her clothing for long duration.

More recently attention has been turned towards the fibre used in the manufacture of the knitted fabric, its effect on the comfort in wear of garments made for underwear and sports purpose. Improvements have enabled the designing of the most interesting fabrics that possess the desired qualities such as good tactile properties, thermal insulation, stretch, and more specifically moisture management, which is directly related to comfort. As the possibilities to expand cotton fibre production are limited, there is considerable potential for further increase in production of 'cellulosics'. It is known that viscose is made from wood pulp, a naturally occurring, cellulose based raw material. As a result, its properties are more similar to those of the natural cellulosic fibres, such as cotton fibre and have good comfort properties. Like other types of rayon, originally marketed as "artificial silk," modal is soft, smooth and breathes well. Its texture is similar to that of cotton or silk. It is cool to the touch and very absorbent due to the largest contact angle compared with viscose and excels. ${ }^{2}$ In spite of being acting like cotton in many ways, modal has significant advantages over it. Even after repeated washes it remains as supple and absorbent as it was on the day it was made. Hence, keeps cool during summers and warm during the winters. In highperformance outdoor activities natural fibres are making comeback due to technological advancement. ${ }^{3}$

Knitted fabric is the most common fabric structure for base layer sportswear due to greater elasticity and stretchability compared to woven fabrics, which is very important for freedom of movement in sports. ${ }^{4}$ With the possibility of various combinations of fabric constructions and yarns used, knitted fabric appears to be the most suitable candidate for functionally adaptive sportswear. Knitted fabrics also mostly have uneven surfaces. A property that makes one feel more comfortable in the aspect of tactile sensations caused by the textile being in direct contact with the skin, when compared to smooth-surfaced woven fabrics of identical fibre compositions. In addition, reduced clinging sensation could be observed when the skin is sweat-wetted due to smaller number of fabric contact points with the skin warranted by the uneven surface. ${ }^{5}$

Garments that are designed for sportswear and active wear should be dynamic or responsive. Through effective thermoregulation and moisture management a clothing system can maximize heat loss when the wearer is hot then increase thermal insulation when perspiration stops. In a sports arena dynamic or responsive garments can enhance performance, control weight build up in clothing and reduce the potential for skin damage. A garment with low intrinsic weight can significantly aid sporting performance. Thus objective of this work was to enhance the thermal properties of sportswear fabrics by the use of cotton and modal fibre.

\section{Materials and methods}

\section{Preparation of samples}

For this work Combed Cotton Ring, and Modal yarns having linear densities 15 Tex, and 20Tex were produced with uniform twist coefficient $\left(\alpha_{\mathrm{e}}=3.3\right)$. The Single Jersey fabric samples were knitted on Single Jersey Circular Knitting Machine of Mayer \& Cie, Model: S43.2 , Germany. Rate of yarn feeding to knitting needles was adjusted by 
the stitch cams. The properties of the knitted fabrics are governed by the two parameters, namely length of loop and shape of loop. Length of loop is one of the structural parameters that determine the pore size in knitted fabric. The amount of yarn feeding in one revolution was changed to produce fabrics with varying loop length values $(\ell$ in $\mathrm{mm}$ ): as $2.7,2.9,3.1$ and 3.3 and hence different tightness factor Combining two fibres, two yarn counts, and four tightness levels, sixteen different samples of Single Jersey fabric were prepared in all (Table 1) (Table 2).

Table I Coding of single jersey fabric knitted with cotton yarn

\begin{tabular}{llll}
\hline Sample no. & $\begin{array}{l}\text { Categorical } \\
\text { variable } \\
\text { fabric code }\end{array}$ & $\begin{array}{l}\text { Yarn } \\
\text { count }\end{array}$ & $\begin{array}{l}\text { Loop length } \\
(\mathbf{m m})\end{array}$ \\
\hline 1 & SCl & 20Tex & 2.7 \\
2 & SC2 & 20Tex & 2.9 \\
3 & SC3 & 20Tex & 3.1 \\
4 & SC4 & 20Tex & 3.3 \\
5 & SC5 & 15Tex & 2.7 \\
6 & SC6 & 15Tex & 2.9 \\
7 & SC7 & 15Tex & 3.1 \\
8 & SC8 & 15Tex & 3.3 \\
\hline
\end{tabular}

Table 2 Coding of single jersey fabric knitted with modal yarn

\begin{tabular}{llll}
\hline Sample no. & $\begin{array}{l}\text { Categorial } \\
\text { variable } \\
\text { fabric code }\end{array}$ & Yarn count & $\begin{array}{l}\text { Loop length } \\
(\mathbf{m m})\end{array}$ \\
\hline 1 & SMI & 20 Tex & 2.7 \\
2 & SM2 & 20 Tex & 2.9 \\
3 & SM3 & 20 Tex & 3.1 \\
4 & SM4 & 20Tex & 3.3 \\
5 & SM5 & 15Tex & 2.7 \\
6 & SM6 & 15Tex & 2.9 \\
7 & SM7 & 15Tex & 3.1 \\
8 & SM8 & 15Tex & 3.3 \\
\hline
\end{tabular}

The knitting was produced under constant machine settings. Full relaxation was carried out of the samples by wet relaxing them in an automatic front loading machine followed by rinsing, spinning and tumble drying and finally conditioning for 24hours in standard atmospheric condition as per Standard wash procedure-IS 1299: 1984.

\section{Fabric weight per unit area}

For measuring GSM standard procedure as per ASTM-D 37761996, IS: 1964-2001 was followed using Mettler make measuring balance, model PB 602-5.

Fabric thickness: For measuring fabric thickness standard procedure as per ASTM-D 1777: 197, IS: 7702: 1975 was used with a Baker make J02 thickness tester.

Fabric tightness factor: The following equation was used to derive the tightness factor $f$ of the knitted fabrics:

$$
K=C . F .=T \cdot F .=\sqrt{T} / \ell
$$

Where $T$ is the yarn count in Tex and $\ell$ is loop length in $\mathrm{cm}$ or $\mathrm{mm} .^{6}$

Air permeability: For measuring Air permeability of the samples ASTM standard D737-1996, was used with SDL Atlas make Air Permeability Tester Model: MO21A. Measurements were performed at a constant pressure drop of $196 \mathrm{~Pa}\left(20 \mathrm{~cm}^{2}\right.$ test area). Ten samples were tested in each group and expressed as $\mathrm{cm}^{3} / \mathrm{cm}^{2} / \mathrm{s}$.

Thermal resistance: How well a material insulates can be indicated by Thermal resistance and is based on the equation:

$$
R=h / \lambda
$$

Where $\mathrm{R}$ is the thermal resistance, $h$ is the thickness and $\lambda$ is the thermal conductivity.

Thermal conductivity: It is indicated by equation

$$
\lambda[W / M k]=Q h / A \Delta T t
$$

Where $Q$ is the amount of conducted heat $(J)$; A is the area through which the heat is conducted $\left(\mathrm{m}^{2}\right) ; \mathrm{t}$ is the time of conductivity $(\mathrm{s}) ; \Delta T$ is the drop of temperature $(k)$; h is the fabric thickness $(m) .{ }^{8,9}$

Thermal conductivity and thermal resistance was measured as per ASTM 1518-2003 using SDL Atlas make Laser Comp model Fox 314.

It is obvious that heat transfer through a fabric is a complex phenomenon affected by many factors. The three major factors in normal fabrics appear to be thickness, entrapped still air and external air movement. To establish a mathematical relationship between the fabric thicknesses, fabric weight on thermal properties, a linear regression equation was used and applied on the thermal properties. Multiple Regression analyses were made between thermal properties and fabric parameters. Thermal properties are defined as dependent variables (Y), loop length; tightness factor, fabric thickness and porosity are defined as independent variables (X). Multiple linear regression analysis has been applied to the measured values and the best fit equations obtained using MINITAB 16. To deduce whether the parameters were significant or not, $p$ values were examined. Ergun emphasized that if $\mathrm{p}$ value of a parameter is greater than 0.05 ( $>0.05$ ), the parameter will not be important and should be ignored. ${ }^{10}$

\section{Results and discussion}

Table 3 shows the thermal comfort properties of cotton single jersey knitted fabrics and Table 4 shows for modal yarns.

\section{Thermal conductivity}

As can be deduced from Figure 1, thermal conductivity value declines with the openness of structure in the case of Single jersey knitted with 15 Tex yarn. The single jersey structure shows an overall better thermal conductivity. This situation can be explained by the amount of entrapped air in the fabric structure. The amount of fibre in the unit area increases and the amount of air layer decreases as the weight increases. As is known, thermal conductivity values of fibres are better than the thermal conductivity of entrapped air. Better correlation coefficient was found for 20Tex knitted fabrics and poor correlation was observed in case of Single jersey knitted with 15Tex. This may be attributed to the fact that even the variety of the same fibre type may influence the changes in the heat transfer. Since physical and 
chemical treatments of cellulose fibres, such as the alkaline treatment of cotton can cause changes of the fibre morphology, changes in their thermal properties can also be expected. The higher value of $\mathrm{R}$ demonstrates the excellence of the relationship and confirms that the regression equation is reliable for prediction of the thermal conductivity in the fabric weight range using $20 \mathrm{Tex}$.

Table 3 Thermal comfort properties of single jersey fabric knitted with cotton yarn

\begin{tabular}{lll}
\hline Fabric code & $\begin{array}{l}\text { Thermal conductivity } \\
(\mathbf{W} / \mathbf{M k})\end{array}$ & $\begin{array}{l}\text { Thermal resistance } \\
\left(\mathbf{m}^{2} \mathbf{k} / \mathbf{W}\right)\end{array}$ \\
\hline $\mathrm{SCl}$ & 0.614 & 0.0129 \\
$\mathrm{SC} 2$ & 0.6026 & 0.016 \\
$\mathrm{SC} 3$ & 0.5954 & 0.018 \\
$\mathrm{SC} 4$ & 0.5901 & 0.0195 \\
$\mathrm{SC} 5$ & 0.6046 & 0.0154 \\
$\mathrm{SC} 6$ & 0.5878 & 0.0202 \\
$\mathrm{SC} 7$ & 0.599 & 0.017 \\
$\mathrm{SC} 8$ & 0.609 & 0.0142 \\
\hline
\end{tabular}

Table 4 Thermal comfort properties of single jersey fabric knitted with modal yarn

\begin{tabular}{lll}
\hline Fabric code & $\begin{array}{l}\text { Thermal conductivity } \\
(\mathbf{W} / \mathbf{M k})\end{array}$ & $\begin{array}{l}\text { Thermal resistance } \\
\left(\mathbf{m}^{2} \mathbf{k} / \mathbf{W}\right)\end{array}$ \\
\hline SMI & 0.6169 & 0.012 \\
SM2 & 0.6128 & 0.013 \\
SM3 & 0.6202 & 0.011 \\
SM4 & 0.6204 & 0.011 \\
SM5 & 0.6163 & 0.012 \\
SM6 & 0.6061 & 0.015 \\
SM7 & 0.613 & 0.013 \\
SM8 & 0.6152 & 0.012 \\
\hline
\end{tabular}

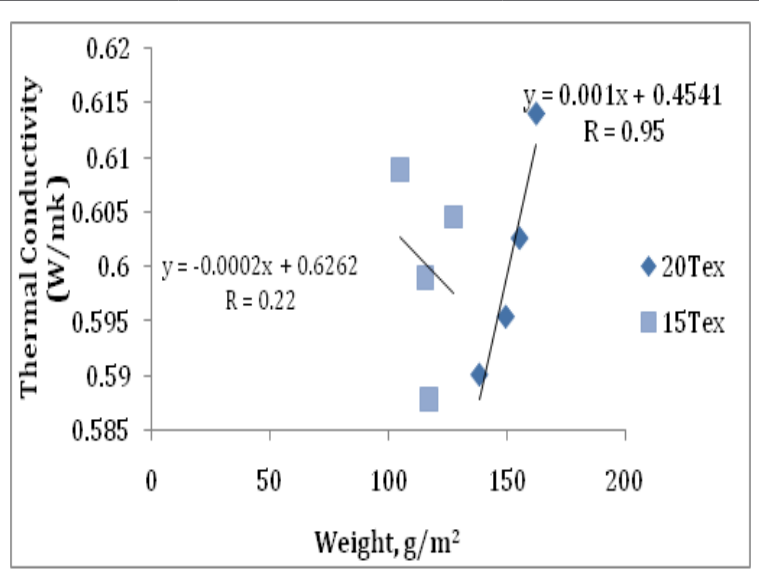

Figure I The relation between Thermal conductivity and weight for single jersey cotton knitted fabrics.

According to Figure 2, the correlation of thermal conductivity with the fabric weight is better.
Modal single jersey fabrics shown better thermal conductivity values among the fabrics investigated. The higher values of $\mathrm{R}$ show that the regression equation is also reliable for prediction of the thermal conductivity in the fabric weight range for both the yarn counts.

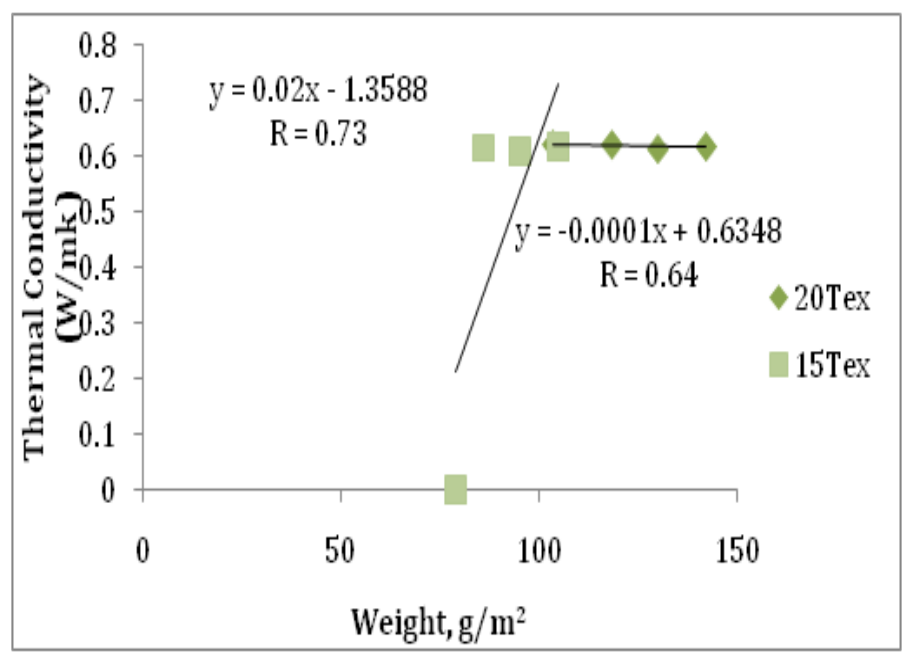

Figure $\mathbf{2}$ The relation between Thermal conductivity and weight for single jersey modal knitted fabrics.

\section{Thermal resistance}

As can be observed from the results (Figure 3), as the fabric thickness increases the thermal resistance increases. Better correlation is shown in case of single jersey knitted fabrics for both the 20Tex and 15 Tex samples. Additionally the higher values of $\mathrm{R}$ also shows the excellence of the relationship and further suggests that the regression equation is reliable for prediction of the thermal resistance in the fabric thickness range with both the yarn counts in single jersey structures. Increasing air permeability, a reduction in thermal resistance takes place. Thickness has a decisive effect on thermal-insulation properties under free-convection conditions resembling those pertaining in a clothing assembly and demonstrates a linear relationship between warmth retention and fabric thickness under these conditions. ${ }^{11}$

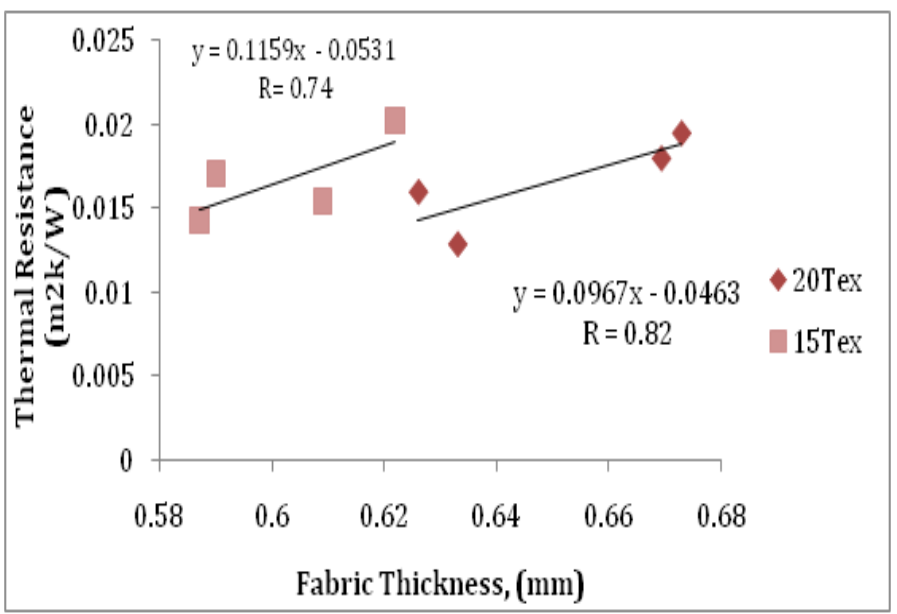

Figure 3 The relation between Thermal resistance and thickness for single jersey cotton knitted fabrics.

In fact the general expectation was to register an inverse relationship between thermal conductivity and thermal resistance, for idealized conditions $R=h / \lambda$; where $R$-thermal resistance, $h$-thickness, $\lambda$ thermal conductivity. ${ }^{12}$ 
The test results also revealed that, as thermal conductivity increases thermal resistance decreases but not linearly. This might be explained by the fabric thickness. If the amount of increase in fabric thickness is more than the amount of increase in thermal conductivity, thermal resistance will also increase. ${ }^{13}$ The amount of increase observed in case of single jersey fabric in thickness is $7.27 \%$ while in thermal conductivity is $4.27 \%$. It was found that as the yarn gets finer the thermal resistance and thermal conductivity decrease which could be ascribed to the higher porosity value of fabrics made from the finer yarns. Previous work reveals that for fabrics made from finer yarns, the air entrapped is less and hence lowers thermal insulation. ${ }^{14}$ The best regression equations for each thermal property for single jersey fabric are given in Table 5.

Tables 6-8 show the regression analysis. Statistical evaluations (Table 6) (Table 7) demonstrated that the $\mathrm{P}$ value corresponding to the coefficient of porosity is very large, which indicates that Table 5 The regression equations between thermal properties and fabric parameters of the single jersey cotton fabrics

\begin{tabular}{ll}
$\begin{array}{l}\text { Thermal } \\
\text { property }\end{array}$ & $\begin{array}{l}\text { Regression equation } \\
\text { (P:porosity h: thickness, I:Iloop Length, } t: \\
\text { tightness factor) }\end{array}$ \\
\hline $\begin{array}{l}\text { Thermal } \\
\text { resistance }\end{array}$ & $\mathrm{R}=-0.170+0.00138 \mathrm{P}+0.105 \mathrm{~h}$ \\
$\begin{array}{l}\text { Thermal } \\
\text { conductivity }\end{array}$ & $\lambda=1.26-0.00489 \mathrm{P}-0.372 \mathrm{~h}$ \\
& \\
Air permeability & $\mathrm{AP}=622-359 \mathrm{t}+2.97 \mathrm{P}-349 \mathrm{~h}$
\end{tabular}

Table 6 Regression analysis: thermal resistance versus porosity, fabric thicknes in the equation of thermal resistance and thermal conductivity, the porosity factor can be avoided since its coefficient is non-significant. Together, porosity and thickness accounted for $58.2 \%$ of the variance in the thermal resistance and $57.3 \%$ of the variance of the thermal conductivity. As per regression analysis (Table 6) it was found that the equation obtained is a good equation as the $\mathrm{R}^{2}$ value $-96.1 \%$.

From the results (Figure 4), it can be seen that, as the fabric thickness increases the thermal resistance increases in the fabric structures considered. Results showed that no correlation exists between the thermal resistance and fabric thickness for single jersey fabrics knitted with $15 \mathrm{Tex}$, proving that the heat transfer process depends not only on the thickness of the fabric but also on the knitting structure, which may be due to dependence of the amount of air in the knitted fabric on the on the order of loops arranged in the fabric. So, it cannot be stated that thickness is the main factor determining the heat transfer through knitted fabric.

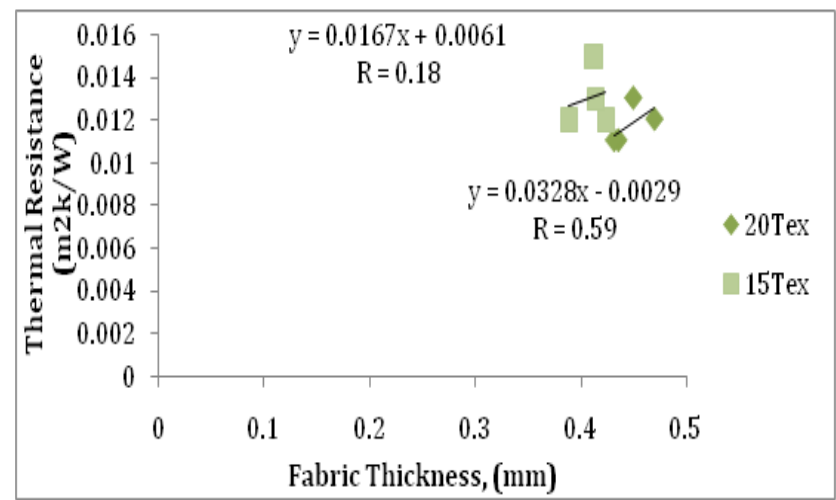

Figure 4 The relation between Thermal resistance and thickness for single jersey modal knitted fabrics.

\begin{tabular}{lllll}
\hline Predictor & Coefficient & SE coefficient & T & P \\
\hline Constant & -0.1697 & 0.07836 & -2.17 & 0.083 \\
Porosity & 0.001376 & 0.0006455 & 2.13 & 0.086 \\
Fabric thickness & 0.10478 & 0.03972 & 2.64 & 0.046 \\
$\mathrm{~S}=0.00193344$ & $\mathrm{R}^{2}=58.2 \%$ & $\mathrm{R}^{2}$ (adjusted) $=41.5 \%$ & &
\end{tabular}

Analysis of variance

$\begin{array}{llllll}\text { Source } & \text { DF } & \text { SS } & \text { MS } & \text { F } & \text { P } \\ \text { Regression } & 2 & 0.000026029 & 0.000013015 & 3.48 & 0.113 \\ \text { Residual Error } & 5 & 0.000018691 & 0.000003738 & & \\ \text { Total } & 7 & 0.00004472 & & & \end{array}$


The best regression equations for each thermal property for single jersey modal fabric are given in Table 9. Tables 10-12 shows regression analysis for modal single jersey fabrics. Statistical evaluation showed that the effect of porosity and thickness on thermal resistance is insignificant for single jersey fabrics. Together, porosity and thickness accounted for $29.4 \%$ of the variance in the thermal resistance and $32.9 \%$ of the variance of the thermal conductivity. As per regression analysis (Table 12) for single jersey it shows that the considered parameter are significant $(\mathrm{p}=0.002)$ and the equation obtained is a good equation as the $\mathrm{R}^{2}$ value $-96.0 \%$.

Table 7 Regression analysis: thermal conductivity versus porosity, fabric thickness

\begin{tabular}{llllll}
\hline Predictor & Coefficient & SE coefficient & T & P & \\
\hline Constant & 1.2621 & 0.2835 & 4.45 & 0.007 & \\
Porosity & -0.004885 & 0.002335 & -2.09 & 0.091 & \\
Fabric thickness & -0.3723 & 0.1437 & -2.59 & 0.049 & \\
S=0.0069942I & $\mathrm{R}^{2}=57.3 \%$ & $\mathrm{R}^{2}$ (adjusted) $=40.3 \%$ & & & \\
Analysis of variance & & & & & \\
Source & $\mathrm{DF}$ & $\mathrm{SS}$ & $\mathrm{MS}$ & $\mathrm{F}$ & $\mathrm{P}$ \\
Regression & 2 & 0.00032855 & 0.00016428 & 3.36 & 0.119 \\
Residual Error & 5 & 0.0002446 & 0.00004892 & & \\
Total & 7 & 0.00057315 & & & \\
\hline
\end{tabular}

Table 8 Regression analysis: air permeability versus porosity, fabric thickness and tightness factor

\begin{tabular}{llllll}
\hline Predictor & Coefficient & SE coefficient & T & P & \\
\hline Constant & 622.2 & 760.4 & 0.82 & 0.007 & \\
Tightness factor & -359.24 & 51.28 & & & \\
Porosity & 2.969 & 6.267 & -7.01 & 0.002 & \\
Fabric thickness & -349 & 358.1 & 0.47 & 0.66 & \\
S=I7.4245 & $\mathrm{R}^{2}=96.1 \%$ & $\mathrm{R}^{2}$ (adjusted)=93.1\% & & \\
Analysis of variance & & & & & \\
Source & $\mathrm{DF}$ & $\mathrm{SS}$ & $\mathrm{MS}$ & $\mathrm{F}$ & $\mathrm{P}$ \\
Regression & 3 & 29641.5 & 9880.5 & 32.54 & 0.003 \\
Residual Error & 4 & $\mathrm{I} 1214.5$ & 303.6 & & \\
Total & 7 & 30856 & & & \\
\hline
\end{tabular}

Table 9 The regression equations between thermal properties and fabric parameters of the single jersey modal fabrics

\begin{tabular}{ll}
\hline Thermal property & $\begin{array}{l}\text { Regression equation } \\
\text { (P:porosity h: thickness, I:loop length, t: tightness factor) }\end{array}$ \\
\hline Thermal resistance & $\mathrm{R}=-0.0463+0.000529 \mathrm{P}+0.024 \mathrm{I} \mathrm{h}$ \\
\hline Thermal conductivity & $\lambda=0.809-0.00182 \mathrm{P}-0.065 \mathrm{~h}$ \\
\hline Air permeability & $\mathrm{AP}=1629-1 \mathrm{I} 1 \mathrm{I} \mathrm{t}-2.2 \mathrm{P}+1650 \mathrm{~h}$ \\
\hline
\end{tabular}

Table 10 Regression analysis: thermal resistance versus porosity, fabric thickness

\begin{tabular}{llllll}
\hline Predictor & Coefficient & SE coefficient & T & P & \\
\hline Constant & -0.04635 & 0.0499 & -0.93 & 0.396 & \\
Porosity & 0.0005294 & 0.0004068 & 1.3 & 0.25 & \\
Fabric thickness & 0.02406 & 0.0342 & 0.7 & 0.513 & \\
S=0.00 129477 & $\mathrm{R}^{2}=29.4 \%$ & $\mathrm{R}^{2}$ (adjusted)=1.2\% & & & \\
Analysis of variance & & & & & \\
Source & $\mathrm{DF}$ & $\mathrm{SS}$ & $\mathrm{MS}$ & $\mathrm{F}$ & $\mathrm{P}$ \\
Regression & 2 & 0.000003493 & 0.000001746 & 1.04 & 0.419 \\
Residual Error & 5 & 0.000008382 & 0.000001676 & & \\
Total & 7 & 0.000011875 & & & \\
\hline
\end{tabular}


Table I I Regression analysis: thermal conductivity versus porosity, fabric thickness

\begin{tabular}{llllll}
\hline Predictor & Coefficient & SE coefficient & T & P & \\
\hline Constant & 0.8092 & 0.1727 & 4.69 & 0.005 & \\
Porosity & -0.001819 & 0.001408 & -1.29 & 0.253 & \\
Fabric thickness & -0.0648 & 0.1183 & -0.55 & 0.608 & \\
S=0.00448050 & $\mathrm{R}^{2}=32.9 \%$ & $\mathrm{R}^{2}$ (adjusted) $=6.0 \%$ & & & \\
Analysis of variance & & & & & \\
Source & $\mathrm{DF}$ & $\mathrm{SS}$ & $\mathrm{MS}$ & $\mathrm{F}$ & $\mathrm{P}$ \\
Regression & 2 & $0.000491 \mathrm{I}$ & 0.00002456 & 1.22 & 0.369 \\
Residual Error & 5 & 0.00010037 & 0.00002007 & & \\
Total & 7 & 0.00014949 & & & \\
\hline
\end{tabular}

Table 12 Regression analysis: air permeability versus porosity, fabric thickness, tightness factor

\begin{tabular}{llllll}
\hline Predictor & Coefficient & SE coefficient & T & P & \\
\hline Constant & 1629 & 1381 & 1.18 & 0.304 & \\
Tightness factor & -1114.9 & 275.6 & -4.04 & 0.016 & \\
Porosity & -2.23 & 10.2 & -0.22 & 0.838 & \\
Fabric thickness & 1650 & 2025 & 0.81 & 0.461 & \\
S 22.3852 & $\mathrm{R}^{2}=96.0 \%$ & $\mathrm{R}^{2}$ (adjusted)=93.0\% & & \\
Analysis of variance & & & & & \\
Source & $\mathrm{DF}$ & $\mathrm{SS}$ & $\mathrm{MS}$ & $\mathrm{F}$ & $\mathrm{P}$ \\
Regression & 3 & 117967 & 39322 & 41.21 & 0.002 \\
Residual Error & 4 & 3816 & 954 & & \\
Total & 7 & 121783 & & & \\
\hline
\end{tabular}

\section{Conclusion}

This paper presents a detailed study of various thermal comfort related properties of single jersey fabrics knitted with cotton and modal yarns, with an aim to select the most adequate fabric for sportswear applications. Based on the results obtained it can be concluded that thanks to the fibre surface and cross-sectional properties, higher fabric thickness and higher fabric cover factor which contribute to heat retention by entrapping still air, the cotton single jersey featured better thermal resistance than the modal. However if the wearer performs mild activities, skin wetness is very low and thermal comfort is managed by skin temperature. In this case, fabrics' air permeability and thermal resistance are determining properties for thermal comfort. Fabrics must have high air permeability and low thermal resistance. Modal fabrics with single jersey structure fulfill these requirements as well as offering the advantages cited at the outset of this work.

\section{Acknowledgments}

The authors acknowledge the support given by the management of Textile Research Application and Development Centre (TRADC), Birla Cellulosic (A unit of Grasim Industries Limited), Kosamba, Gujarat, India during the study.

\section{Conflict of interest}

Author declares there is no conflict of interest in publishing the article.

\section{References}

1. Öztürk MK, Nergis B, Candan C. A study of wicking properties of cotton-acrylic yarns and knitted fabrics. Text Res J. 2011;81(3):324-328.

2. Bhattacharya SS, Ajmeri JR. Air permeability of knitted fabrics made from regenerated cellulosic fibres. Int JEngg Res Dev. 2014;10(7):16-22.

3. Ajmeri JR. Critical study to improve the water transport properties of knitted fabrics. MS University of Baroda, India; 2014. p. 264.

4. Behera BK. Comfort behavior of cotton polypropylene based bi-layer knitted fabrics. Asian Text J. 2002. p. 61- 67.

5. Troynikov O, Wardininsih W. Moisture management properties of wool/ polyester and wool/bamboo knitted fabrics for the sportswear base layer. Text Res J. 2011;81(6):621-631.

6. Baird K, Foulds RA. Felting Shrinkage of Plain-Knitted Wool Fabrics: Its Dependence upon Fabric Structure and Shrinkproofing Level. Text Res J. 1968;38(7):743-753.

7. Frydrych I, Dziworska G, Bilska J. Comparative Analysis of the Thermal Insulation Properties of Fabrics Made of Natural and ManMade Cellulose Fibres. J Fibr Textil East Eur. 2002;4(39):40-44.

8. Ucar N, Yilmaz T. Thermal properties of $1 \times 1,2 \times 2,3 \times 3$ rib knit fabrics. Fibr Textil East Eur. 2004;12(3):34-38.

9. Morton WE, Hearle JWS. Physical Properties of Textile Fibres. 4th ed. Cambridge: Woodhead Publishing; 2008. p. 1-11.

10. Ergun M. SPSS for windows. Turkey: Ocak Publisher; 1995. 
11. Slater K. Comfort properties of textiles. Textile Progress. 1977;9(4):1-70

12. Ajmeri JR, Bhattacharya SS. Excel single jersey fabrics are suitable for warmer climate. Textile Asia. 2015;46(8):41-45.

13. Chidambaram P, Govindan R, Venkatraman KC. Study of thermal comfort properties of cotton/regenerated bamboo knitted fabrics. African J Basic \& Applied Sci. 2012;4(2):60-66.
14. Tyagi GK, Sharma D. Thermal comfort characteristics of polyester cotton MVS yarn fabrics. Indian J Fib Text Res. 2005;30(4):363-370. 